\title{
ANTECIPAÇÃO DA MATURAÇÃO DA UVA 'RUBI' PRODUZIDA FORA DE ÉPOCA NO NOROESTE DO ESTADO DO PARANÁ ${ }^{1}$
}

\author{
SÉRGIO RUFFO ROBERTO², FÁBIO YAMASHITA², HERNANDES TAKESHI KANAI ${ }^{3}$, MARCOS YUTAKA YANO², \\ EVANDRO MACENTE SASANO ${ }^{4}$, WERNER GENTA ${ }^{4}$
}

\begin{abstract}
RESUMO - O presente trabalho teve por objetivo avaliar o efeito do anelamento de tronco na antecipação da maturação de uvas finas de mesa produzidas fora de época, na região noroeste do Paraná. A técnica foi avaliada em três parreiras de videira 'Rubi' (Vitis vinifera L.) e consistiu na remoção da casca do tronco de aproximadamente 3-4 mm de largura, com um incisor de lâmina dupla, a uma altura de 1,5 m do solo. O anelamento foi aplicado no início do amolecimento das bagas, o que se deu no início de abril de 2001. O delineamento experimental para as três áreas experimentais foi o de blocos ao acaso, com dois tratamentos (anelamento e testemunha) e quatro repetições, sendo cada parcela composta por uma planta útil. Avaliaram-se, semanalmente, a partir da instalação do experimento, o teor de sólidos solúveis totais (SST) e acidez total titulável (ATT) das bagas até a colheita, em um total de seis amostragens. Tanto o teor de SST como a ATT apresentaram um comportamento linear em função do tempo para os dois tratamentos, e através de regressão linear foi estimado o período para que os cachos atingissem a plena maturação, considerando-se $14{ }^{\circ} B$ rix como padrão. O período de antecipação da maturação de cachos pelo uso do anelamento em relação à testemunha variou de 3 a 12 dias. Não foram observadas diferenças em relação ao decréscimo do teor de ATT entre os tratamentos nas parreiras avaliadas.
\end{abstract}

Termos para indexação: Vitis vinifera L., videira, sólidos solúveis totais, acidez total titulável.

\section{MATURATION HASTENING OF 'RUBI' TABLE GRAPE PRODUCED OUT OF SEASON IN THE NORTHWEST OF PARANÁ STATE, BRAZIL}

\begin{abstract}
This research was an attempt to evaluate the trunk girdling effect to hasten the maturation of table grapes produced out of season in the northwest of Parana state, Brazil. The trial was carried out in three vineyards of 'Rubi' (Vitis vinifera L.) and the girdling consisted of removing a narrow ring of bark entirely round of the trunk using a double-bladed $3.1 \mathrm{~mm}$ knife, $1.5 \mathrm{~m}$ far from the ground. The technique was applied during the early ripening period, which took place in early April, 2001. A randomized block design with two treatments (girdling and control) and four replications was used as an statistical model for each location. Each plot was composed by one plant. Total soluble solids (TSS) and titratable acidity (TTA) were evaluated weekly through berries samples collection, from the establishment of the experiment up to its harvesting, totalizing six samplings for each location. Both TSS and TTA presented linear correlation as function of time for both treatments and through linear regression, it was estimated the period the clusters reached the maturation, considering $14^{\circ}$ Brix as standard. The period of maturation hastening in girdled plants in relation to the control ones ranged from 3 to 12 days. There was no difference in relation to the TTA decrease pattern in berries in both girdled and control treatments for all locations.
\end{abstract}

Index terms: Vitis vinifera L., grapevine, soluble solids, titratable acidity.

O uso de técnicas que favoreçam a antecipação da maturação de uvas finas de mesa é extremamente desejado na região noroeste do Paraná, pois a remuneração pode ser maior para o produtor que disponha de uvas maduras antes do pico de maior oferta do produto no mercado. Além disso, em anos onde ocorrem geadas, a poda de inverno pode ser retardada, resultando em um período de colheita a partir de janeiro, onde os preços são muito menores, o que poderia ser minimizado empregando-se técnicas para antecipar a maturação dos cachos.

Entre as possíveis práticas para antecipar a maturação está o anelamento ou incisão anelar. Esta técnica consiste na retirada completa de um anel da casca do tronco ou de ramos lenhosos com largura variável de 3,1 a $6,3 \mathrm{~mm}$. O efeito fisiológico primário é o acúmulo de carboidratos nas partes acima da lesão devido à interrupção temporária da translocação da seiva elaborada para o tronco e raízes, antecipando a maturação dos cachos (Pommer et al., 1991).

$\mathrm{O}$ anelamento, em função da época e da variedade, pode ser realizado com diferentes objetivos, dentre eles: melhorar o pegamento ou aumentar o número de bagas nos cachos, principalmente para as variedades com excessivo abortamento de flores; aumentar o tamanho das bagas, principalmente para as variedades sem sementes, que têm dificuldade no crescimento das bagas; e, finalmente, antecipar a maturação. Quando se visa a este último objetivo, a técnica deve ser realizada durante a "véraison", fase esta que corresponde ao início do amolecimento das bagas nas variedades brancas ou ao início da formação de cor nas bagas das variedades de uvas rosadas ou pretas (Winkler et al., 1974; Carreño et al., 1998; Terra et al., 1998). Isso deve-se ao fato de que, a partir desta fase fenológica, observa-se um massivo acúmulo de açúca- res nas bagas (Mullins et al., 1994).

Entretanto, pouquíssima informação está disponível a respeito do uso do anelamento do tronco para antecipar a maturação de uvas finas de mesa no Paraná e no Brasil, o que motivou a realização desta pesquisa. Tendo em vista estes aspectos, o trabalho teve por objetivo determinar o comportamento da maturação de cachos produzidos fora de época da videira 'Rubi' ( $V$. vinifera $L$.) submetida ao anelamento de tronco na região noroeste do Estado do Paraná.

O presente trabalho foi realizado em três parreiras comerciais de videira cultivar Rubi (Vitis vinifera $\mathrm{L}$.) enxertada sobre IAC-766 'Campinas' conduzidas no sistema latada, com cinco anos de idade, e localizadas no município de Marialva-PR.

O estudo foi realizado sobre a produção de uvas fora de época na região, oriunda da poda de verão, realizada em meados de janeiro de 2001, após a colheita da produção proveniente da poda de inverno. As videiras, nas três propriedades, foram conduzidas com poda longa (8 gemas), sendo as gemas apicais estimuladas com cianamida hidrogenada a $2,5 \%$.

O anelamento consistiu na remoção da casca do tronco das plantas de, aproximadamente, 3-4 mm de largura, utilizando-se de um incisor de lâmina dupla a uma altura de 1,5 m do solo, durante o início do amolecimento das bagas ("véraison") (Winkler et al., 1974), o que se deu no início do mês de abril de 2001.

O delineamento experimental para as três áreas experimentais foi o de blocos ao acaso com dois tratamentos (testemunha e anelamento) e quatro repetições, sendo cada parcela composta por uma planta útil. A partir da instalação do experimento, foram avaliados, a cada 7 dias, o teor

1 (Trabalho 178/2001). Recebido: 10/11/2001. Aceito para publicação: 06/09/2002.

2 Professor Adjunto, Dr. Universidade Estadual de Londrina - UEL. Centro de Ciências Agrárias. Caixa Postal 6001. 86051-990. Londrina, PR. Autor correspondente: sroberto@uel.br

3 Acadêmico do Curso de Graduação em Agronomia e Bolsista de Iniciação Científica do CNPq. Universidade Estadual de Londrina - UEL. Centro de Ciências Agrárias. Caixa Postal 6001. 86051-990. Londrina, PR.

4 Eng. Agr. Associação Norte Paranaense de Estudos em Fruticultura - ANPEF. Rua Atílio Ferri, 336. Marialva, PR. 
de sólidos solúveis totais (SST) e a acidez total titulável (ATT), através da coleta de oito bagas por parcela, sendo duas de cada quadrante da planta, as quais foram retiradas da porção terminal de cachos tomados ao acaso, até a colheita, em um total de seis amostragens para cada área experimental. Para tanto, após a trituração das bagas de cada amostra, o teor de SST foi determinado em refratômetro de bancada com compensação de temperatura, sendo o suco previamente filtrado em algodão e o resultado expresso em ${ }^{\circ}$ Brix (Instituto Adolfo Lutz, 1985). A determinação da ATT foi realizada por titulação do suco com solução padronizada de $\mathrm{NaOH} 0,1 \mathrm{~N}$, e o resultado expresso em \% de ácido tartárico (Instituto Adolfo Lutz, 1985)

A partir dos dados obtidos, obteve-se, através de análise de regressão linear, o comportamento das variáveis analisadas (SST e ATT) de cada tratamento em função do tempo para cada uma das três áreas experimentais, determinando-se as seguintes variáveis: tempo estimado (em dias), após a aplicação dos tratamentos, para que os cachos completassem sua plena maturação, considerando-se $14^{\circ}$ Brix como padrão, e a evolução do teor de ATT em função do tempo pós-anelamento. Para a determinação dos coeficientes e parâmetros estatísticos das regressões lineares, foi utilizado o programa StatisticaÒ 5.0 (Statsoft, 1995).

A evolução do teor de SST no mosto da uva 'Rubi', no período em que foram realizadas as amostragens, ajustou-se significativamente à regressão linear $(P<0,01)$ nas três áreas experimentais avaliadas (Figura 1 e Tabela 1). Este acúmulo crescente e linear de açúcares em videiras, a partir do início da maturação das bagas, foi anteriormente relatado por outros autores (Carrol \& Marcy, 1982; Harrel \& Willians, 1987). Entretanto, observa-se que as curvas do tratamento onde se empregou o anelamento do tronco, se posicionaram acima das curvas das plantas não aneladas (testemunha), indicando haver diferenças no comportamento do acúmulo de SST entre os tratamentos.
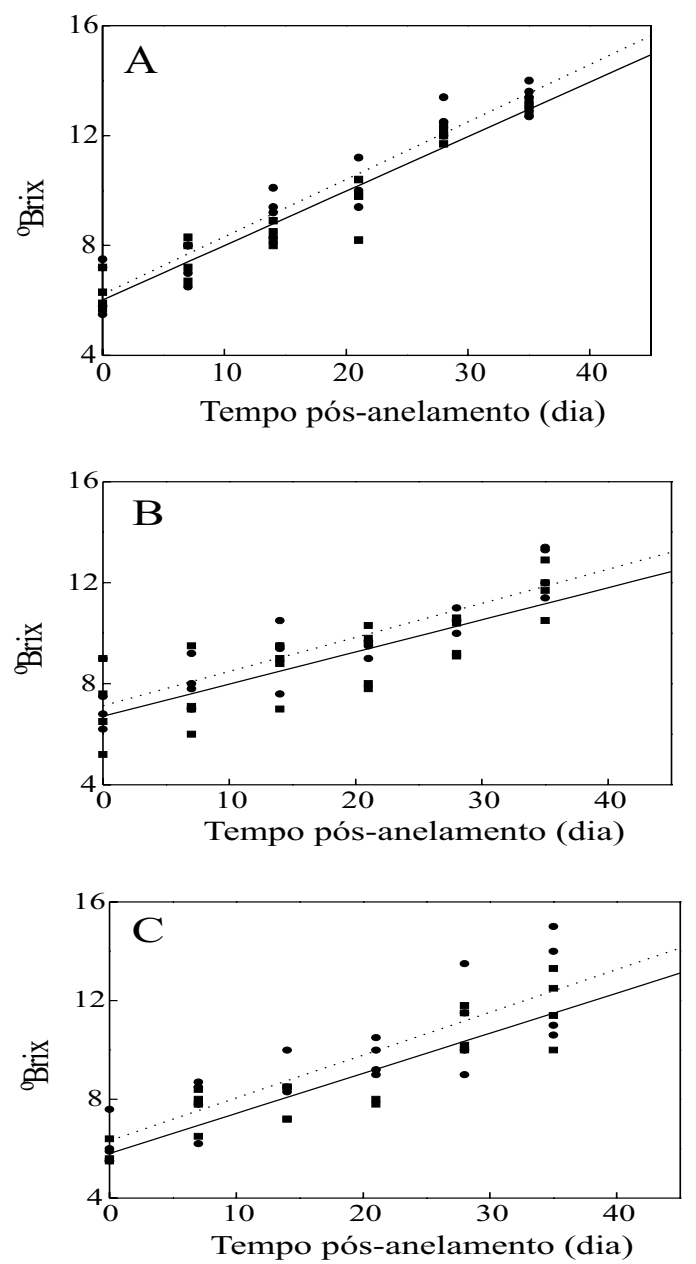

FIGURA 1 - Variação do teor de sólidos solúveis totais ( ${ }^{\circ}$ Brix) de cachos de videira 'Rubi' (Vitis vinifera L.) em função do tempo pós-anelamento. A: Parreira 1; B: Parreira 2; C: Parreira 3.

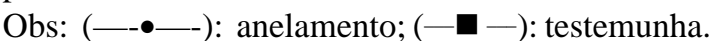

TABELA 1 - Evolução do teor de sólidos solúveis totais (SST) ( ${ }^{\circ}$ Brix) de cachos de videira 'Rubi' (Vitis vinifera $\mathrm{L}$.) em função do tempo pós-anelamento. SST $\left({ }^{\circ}\right.$ Brix $)=\mathrm{A}+\mathrm{B} x$ Tempo (dia). Marialva-PR. 2001.

\begin{tabular}{|c|c|c|c|c|c|}
\hline Parreira & Tratamento & $\begin{array}{c}\text { A } \\
\left({ }^{0} \text { Brix }\right)\end{array}$ & $\begin{array}{c}\text { B } \\
\left({ }^{0} \text { Brix } / \text { dia }\right)\end{array}$ & $\begin{array}{l}\text { Tempo para } \\
\text { atingir } 14^{\circ} \mathrm{Brix} \\
\text { (dias) }\end{array}$ & $\mathbf{R}^{2 \mathrm{a} /}$ \\
\hline \multirow[t]{2}{*}{1} & Testemunha & $6,01 \quad 0,25$ & $0,20 \quad 0,01$ & 403 & $0,93 *$ \\
\hline & Anelamento & $6,22 \quad 0,27$ & $0,21 \quad 0,01$ & 373 & $0,92^{*}$ \\
\hline \multirow[t]{2}{*}{2} & Testemunha & $6,71 \quad 0,43$ & $0,12 \quad 0,02$ & 6116 & $0,64 *$ \\
\hline & Anelamento & $7,13 \quad 0,34$ & $0,14 \quad 0,02$ & 498 & $0,76^{*}$ \\
\hline \multirow[t]{2}{*}{3} & Testemunha & $\begin{array}{ll}5,80 & 0,38\end{array}$ & $0,16 \quad 0,02$ & $51 \quad 10$ & $0,79 *$ \\
\hline & Anelamento & $6,32 \quad 0,47$ & $0,17 \quad 0,02$ & 456 & $0,74 *$ \\
\hline
\end{tabular}

${ }^{a}$ : Coeficiente de determinação da análise de regressão; *: Significativo $(P<0,01)$.

Para a Parreira 1, o anelamento do tronco propiciou uma antecipação da maturação de apenas três dias em relação à testemunha (Tabela 1), enquanto, nas Parreiras 2 e 3 , a técnica resultou em períodos maiores de antecipação (12 e 6 dias, respectivamente). Estes resultados são semelhantes aos obtidos por Carreño et al. (1998) que determinaram que o anelamento realizado no início da maturação de cachos da videira 'Itália' aumentou significativamente o teor de SST nas bagas, antecipando a maturação em cinco dias em relação às plantas não aneladas.

Observa-se que o incremento diário de SST foi superior nos cachos cujas videiras foram submetidas ao anelamento nas três parreiras (Tabela 1), o que resultou na antecipação de sua maturação, mostrando o efeito fisiológico de maior acúmulo de carboidratos nas partes acima do anelamento, conforme relatado por Weaver \& McCune (1959), Harrel \& Willians (1987) e Pommer et al. (1991).

Mullins et al. (1994) descreveram que o acúmulo de SST é dependente da fotossíntese e da importação de sacarose das folhas, a qual é posteriormente hidrolisada em glicose e frutose nas bagas. Este acúmulo representa uma significativa mudança no modelo de translocações dos produtos fotossintetizados. Antes da "véraison", as brotações do ápice são os maiores drenos da planta. A partir deste período, que corresponde à terceira fase do desenvolvimento da baga descrita por Matthews et al. (1987), observa-se um massivo acúmulo de SST nos frutos. Assim, a interrupção temporária da translocação da seiva para as raízes, devido ao anelamento, explica a antecipação da maturação da uva mostrada neste trabalho.

Winkler et al. (1974) relataram que a efetividade da aplicação desta técnica é também influenciada pelas características de cultivo, como o nível de produção e vigor da planta. Estes autores enfatizam que as melhores respostas quanto à antecipação da maturação são obtidas em plantas com pouca a moderada produção, sendo que, em vinhedos em condições de excesso de carga, crescimento muito ativo ou clima mais frio, pode haver pouca ou nenhuma resposta à aplicação do anelamento. Diante destas considerações, as diferenças nos períodos de antecipação da maturação dos cachos, observadas nas três parreiras avaliadas, podem ser atribuídas à produção e ao vigor, pois muito embora estes fatores não tenham sido mensurados, as demais características horticulturais das áreas experimentais, como idade da planta, porta-enxertos e solo, eram semelhantes. Desta forma, espera-se que a antecipação da maturação da uva pelo uso do anelamento seja variável em função das características de cultivo de cada parreira.

A evolução da ATT das bagas não parece ter sido afetada pelo anelamento, sendo que, para todas as parreiras, as curvas de decréscimo de ATT se apresentaram de forma equivalente para todos os tratamentos (Figura 2), ajustando-se significativamente à regressão linear $(P<0,01)$, conforme apresentado na Tabela 2.

Mullins et al. (1994) descreveram que a concentração de ácidos orgânicos presentes nas bagas, que representam mais de $90 \%$ em sua composição pelos ácidos tartárico e málico, decresce significativamente a partir do início do amolecimento das bagas, devido a diversos fatores. 

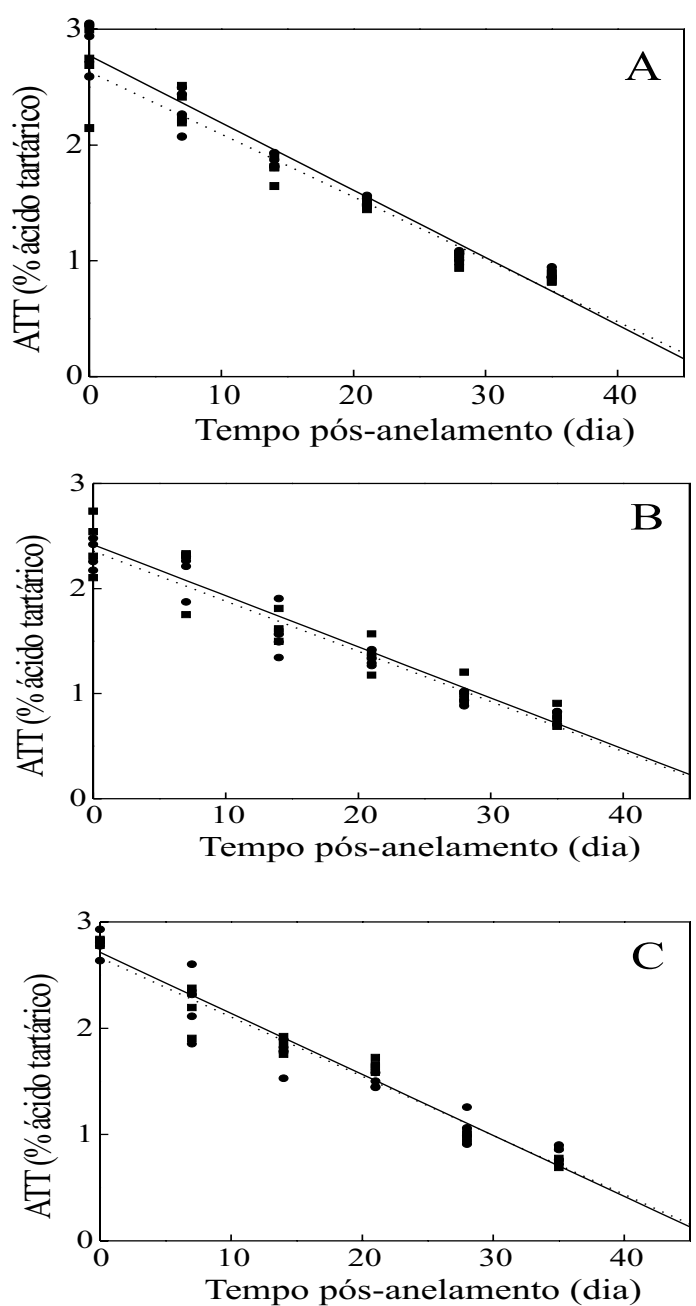

FIGURA 2 - Variação da acidez total titulável (ATT) de cachos de videira 'Rubi' (Vitis vinifera L.) em função do tempo pósanelamento. A: Parreira 1; B: Parreira 2; C: Parreira 3. Obs: (--•-): anelamento; (- - - ): testemunha.

A partir da "véraison", verifica-se que não ocorre uma redução da quantidade de ácido tartárico "por baga" e, sim, sua diluição crescente devido ao aumento do volume das bagas. Por outro lado, observa-se, a partir desta fase, que a concentração de ácido málico sofre significativa redução devido à alteração do metabolismo da sacarose exógena (Possner et al., 1983), até que o seu teor se estabilize em um patamar constante próximo à maturação plena dos cachos (Carrol \& Marcy, 1982). Desta forma, como estes ácidos orgânicos já se encontravam presentes nas bagas no momento em que as plantas foram aneladas, não ocorreram diferenças em seu comportamento entre os tratamentos, uma vez que os processos que determinam sua redução nos frutos, não são influenciados pela prática do anelamento, conforme descrito acima.

Considerando os resultados obtidos neste trabalho, pode-se inferir que o anelamento do tronco apresenta grande potencial para ante- cipar a maturação de uvas finas de mesa, o que pode resultar em significativos ganhos para os viticultores do noroeste do Estado do Paraná, porém fatores inerentes ao cultivo devem ser considerados, como o nível de produção e o vigor das plantas.

\section{AGRADECIMENTOS}

Os autores expressam seus agradecimentos à ANPEF (Associação Norte Paranaense de Estudos em Fruticultura), pelo apoio humano e financeiro ao trabalho.

\section{REFERÊNCIASBIBLIOGRÁFICAS}

CARREÑO, J., FARAY, S., MARTINEZ, A. Effects of girdling and covering mesh on ripening, colour and fruit characteristics of 'Italia' grapes. Journal of Horticultural Science and Biotechnology, Ashford, v.73, n.1, p.103-106, 1998.

CARROL, D.E.; MARCY, J.E. Chemical and physical changes during maturation of Muscadine grapes (Vitis rotundifolia). American Journal of Enology and Viticulture, Davis, v.33, n.3, p.168-172, 1982.

HARREL, D.C.; WILLIANS, L.E. The influence of girdling and gibberellic acid application at fruitset on Ruby Seedless and Thompson Seedless grapes. American Journal of Enology and Viticulture, Davis, v.38, n.2, p.83-88, 1987.

INSTITUTO ADOLFO LUTZ. Normas analíticas do Instituto Adolfo Lutz: métodos químicos e físicos para análise dos alimentos. 3.ed. São Paulo: Instituto Adolfo Lutz, 1985. v.1,371p.

MATTHEWS, M.A.; CHENG, G.; WEINBAUM, S.A. Changes in water potential and dermal extensibility during grape berry development. Journal of the American Society for Horticultural Science, Alexandria, v.112, n.2, p.314-319, 1987.

MULLINS, M.G.; BOUQUET, A., WILLIANS, L.E. Biology of the grapevine. New York: University of Cambridge, 1994. 239p.

POMMER, C.V., TERRA, M.M., PIRES, E.J.P., PICININ, A.H., PASSOS, I.R.S. Efeito do anelamento na maturação de uvas com sementes. Revista Brasileira de Fruticultura, Cruz das Almas, v.13, n.3, p.147150,1991.

POSSNER, D., RUFFNER, H.P., RAST, D.M. Regulation of malic acid metabolism in berries of Vitis vinifera. Acta Horticulturae, Wageningen, n.139, p.117-122, 1983.

STATSOFT STATISTICA for Windows - Computer program manual. Tulsa: Statsoft, 1995.

TERRA, M.M.; PIRES, E.J.P.; NOGUEIRA, N.A.M. Tecnologia para a produção de uva Itália na região noroeste do Estado de São Paulo. 2.ed. Campinas: Coordenadoria de Assistência Técnica Integral, 1998. 81p. (Documento Técnico 97)

WEAVER, R.J.; McCUNE, S.B. Girdling: its relation to carbohydrate nutrition and development of Thompson Seedless, Red Malaga and Ribier grapes. Hilgardia, Oakland, v.28, n.16, p.421-456, 1959.

WINKLER, A.J., COOK, J.A., KLIEWER, W.M., LIDER, L.A. General viticulture. Berkeley: University of California Press, 1974. 710p. 